\title{
Method Development and Validation for Determination of Febuxostat from Spiked Human Plasma Using RP-HPLC with UV Detection
}

\author{
Monita Gide, Pankaj Sharma, Ravindra Saudagar, and Birendra Shrivastava \\ School of Pharmaceutical Sciences, Jaipur National University, Jaipur-Agra Bypass, Near New RTO Office, Jagatpura, \\ Jaipur, Rajasthan 302017, India \\ Correspondence should be addressed to Monita Gide; monitagide@gmail.com
}

Received 18 July 2014; Accepted 12 November 2014; Published 27 November 2014

Academic Editor: Susana Casal

Copyright (C) 2014 Monita Gide et al. This is an open access article distributed under the Creative Commons Attribution License, which permits unrestricted use, distribution, and reproduction in any medium, provided the original work is properly cited.

\begin{abstract}
A rapid, simple, selective, and specific reverse phase high performance liquid chromatography (RP-HPLC) method with UV detection $(315 \mathrm{~nm})$ was developed and validated for estimation of febuxostat from spiked human plasma. The analyte and internal standard (diclofenac) were extracted using LLE with diethyl ether. The chromatographic separation was performed on Shodex C$18-4 \mathrm{E}(5 \mu \mathrm{m} ; 250 \times 4.6 \mathrm{~mm})$ with a mobile phase comprised of methanol : acetate buffer $\mathrm{pH} 4,20 \mathrm{mM}(90: 10 \mathrm{v} / \mathrm{v})$, at a flow rate of $1 \mathrm{~mL} / \mathrm{min}$. Febuxostat was well resolved from plasma constituents and internal standard. The calibration curve was linear in the range of $250-8000 \mathrm{ng} / \mathrm{mL}$. The heteroscedasticity was minimized by using weighted least square regression with weighing factor of $1 / x$. The intraday and interday $\%$ RSD was less than 15 . Results of recovery studies prove the extraction efficiency. Stability data indicated that febuxostat was stable in plasma after three freeze thaw cycles and upon storage at $-20^{\circ} \mathrm{C}$ for 30 days.
\end{abstract}

\section{Introduction}

The determination of drugs from biological fluids is essential to pharmacologic and pharmacokinetic studies, which include determinations of the absorption, distribution, metabolism, and elimination of drugs in animals and humans. Biologic fluid assays also support studies of correlations of blood tissue levels of drugs and pharmacologic effects (pharmacodynamics), which are sought during drug development [1-3]. Sample preparation for analysis of biological samples is one of the key factors that determine the extent of recovery of the analyte from the sample matrix. In this context, LLE is the most widely used method for extracting analytes from aqueous biological fluids and separating them from endogenous interferants. LLE also provides a simple means of concentrating the analyte by evaporation of the solvent. The analyte is isolated by portioning between the organic phase and the aqueous phase $[4,5]$.

Febuxostat is chemically 2-[3-cyano-4-(2-methylpropoxy)phenyl]-4-methylthiazole-5-carboxylic acid (Figure 1). It is a non-purine selective inhibitor of xanthine oxidase that is indicated for use in the treatment of hyperuricemia and gout. Febuxostat inhibits xanthine oxidase noncompetitively, therefore reducing production of uric acid [6]. Several methods are reported in literature for estimation of febuxostat from rat plasma using techniques like LC-MS/MS [7-10], LC-MS [11] and HPLC with fluorescence detection [12-15]. However the methods reported involved use of costly sample preparation tools like solid phase extraction and relied on less commonly available internal standard. Hence the purpose of the present work was to develop a simple economical LLERP-HPLC-UV method for the estimation of febuxostat from spiked human plasma.

\section{Experimental}

2.1. Equipment and Materials. The analysis was performed using Agilent 1200 series quaternary pump HPLC system equipped with variable wavelength programmable UV detector with precision loop injector (Rheodyne $20 \mu \mathrm{L}$ ). $50 \mu \mathrm{L}$ Hamilton injection syringe was used for sample injection. The data was processed using Chemstation (B.02.01) software. 


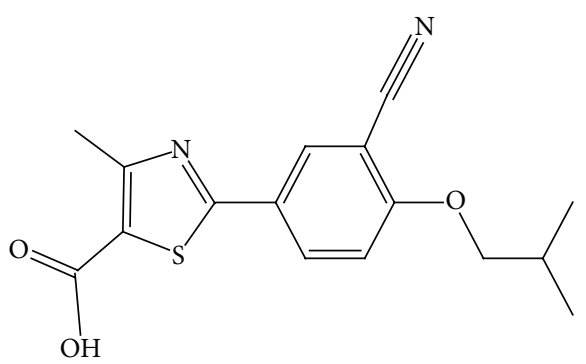

FIGURE 1: Chemical structure of febuxostat.

Pharmaceutical grade febuxostat was kindly provided by Ammi Life Sciences, Gujarat, India, and diclofenac by Aarti Drugs, Mumbai, India. Blank human plasma was procured as a gift sample from National Plasma Fractionation Centre, KEM Hospital, Mumbai, India. Plasma from six different sources was mixed thoroughly to get pooled blank plasma. Methanol and water used in the analysis were of HPLC grade and all other chemicals were of AR grade. All chemicals were purchased from SD Fine Chemicals, Mumbai, India. The $0.45 \mu \mathrm{m}$ Nylon membrane filters were purchased from Pall India Pvt. Ltd. Mumbai, India.

2.2. Preparation of Calibration Curve (CC) Standards and Quality Control (QC) Samples. The stock solution $(1 \mathrm{mg} / \mathrm{mL})$ of febuxostat was prepared in methanol and this was then appropriately diluted with methanol to get working standard solutions having concentrations $10,20,40,80,160$, and $320 \mu \mathrm{g} / \mathrm{mL}$. $1 \mathrm{~mL}$ aliquots of blank human plasma were spiked with $25 \mu \mathrm{L}$ of the working standard solutions to get CC standards containing 250, 500, 1000, 2000, 4000, and $8000 \mathrm{ng} / \mathrm{mL}$ of guaifenesin. The QC samples were similarly prepared to contain three concentrations $[500 \mathrm{ng} / \mathrm{mL}$ lower quality control (LQC), $2000 \mathrm{ng} / \mathrm{mL}$ middle quality control (MQC), and $7500 \mathrm{ng} / \mathrm{mL}$ higher quality control (HQC)].

\subsection{Preparation of Internal Standard Stock Solution and} Working Standard Solution. The stock solution $(1 \mathrm{mg} / \mathrm{mL})$ of diclofenac was prepared in methanol and then appropriately diluted with methanol to get working standard solution of $240 \mu \mathrm{g} / \mathrm{mL}$.

2.4. Sample Preparation. $1 \mathrm{~mL}$ of human plasma spiked sample was taken in a glass tube of $15 \mathrm{~mL}$ capacity. To this $5 \mathrm{~mL}$ of diethyl ether was added and the contents of the tube were mixed on a vortex mixer for $2 \mathrm{~min}$. The tubes were kept in an inclined position on a reciprocating shaker at 100 strokes per min for $45 \mathrm{~min}$. After extraction, the tubes were centrifuged at $3000 \mathrm{rpm}$ for $15 \mathrm{~min}$ at $4^{\circ} \mathrm{C} .3 \mathrm{~mL}$ of the organic layer was pipetted out into a separate tube and evaporated to dryness under a stream of nitrogen. The residue was reconstituted in $250 \mu \mathrm{L}$ of the mobile phase and subjected to chromatographic analysis using the optimized chromatographic conditions.

2.5. Chromatographic Conditions. The chromatographic separation was performed in a Shodex C 18-4E column $(5 \mu \mathrm{m}$;
$250 \times 4.6 \mathrm{~mm}$, Showa Denko America Inc., USA). The mobile phase consisted of a mixture of methanol : acetate buffer $\mathrm{pH} 4,20 \mathrm{mM}(90: 10 \mathrm{v} / \mathrm{v})$. The injection volume was $20 \mu \mathrm{L}$ and the run time was $10 \mathrm{~min}$. Detection was carried out at $315 \mathrm{~nm}$.

2.6. Calibration Studies. All CC standards were analyzed in six replicates and the data of concentrations and the corresponding area ratios of febuxostat to internal standard were subjected to unweighted and weighted least square linear regression. The equations so generated were used to calculate the interpolated concentrations of the CC standards and the \% relative error (\%RE) was calculated for each CC standard as

$$
\begin{aligned}
& \% \mathrm{RE} \\
& =\frac{\text { Interpolated concentration }- \text { nominal concentration }}{\text { Nominal concentration }} \\
& \quad \times 100 .
\end{aligned}
$$

The calibration model that resulted in minimum total \% RE for the interpolated concentrations of CC standards was selected as the one that gave least error.

2.7. Validation. The developed method was validated as per the recommendations of US FDA Guidance for Industry: Bioanalytical Method Validation [16]. Selectivity was studied at the lower limit of quantification (LLOQ) of $250 \mathrm{ng} / \mathrm{mL}$ by comparing the blank responses of plasma from six different sources with the peak areas afforded by the LLOQ samples. Accuracy and precision were studied by analyzing five replicates of the lower quality control (LQC), middle quality control (MQC), and higher quality control (HQC) samples over five days. The concentration of febuxostat in the QC samples was determined by referring to the area ratio of the drug to internal standard, obtained from the QC samples, to the calibration equation generated on the same day. The accuracy was estimated as the mean $\%$ RE while the precision was measured in terms of \%RSD.

The recovery of the extraction procedure was calculated by comparing the peak areas of the processed QC samples to those of corresponding standard dilutions.

Stability of febuxostat was evaluated under various conditions, namely, three freeze thaw cycles, stability at room temperature for $6 \mathrm{~h}$, and short term stability at $-20^{\circ} \mathrm{C}$. For the determination of freeze thaw stability, five replicates of LQC and HQC samples were frozen at $-20^{\circ} \mathrm{C}$ for a minimum of $24 \mathrm{~h}$ and then allowed to thaw unassisted at room temperature. For short term room temperature stability, five replicates of LQC and HQC samples were kept at room temperature for $6 \mathrm{~h}$, short term stability at $-20^{\circ} \mathrm{C}$ was determined by using five replicates of LQC, and HQC was kept at $-20^{\circ} \mathrm{C}$ for one month. The amount of the drug in stability samples was found and the \% nominal and \%RSD were calculated. 
TABLE 1: Area ratio from calibration experiments on febuxostat.

\begin{tabular}{lcc}
\hline CC number & Amount of drug $(\mathrm{ng} / \mathrm{mL})$ & Mean area ratio $\left( \pm \mathrm{SD}^{*}\right)$ \\
\hline 1 & 250 & $0.197 \pm 0.009$ \\
2 & 500 & $0.321 \pm 0.013$ \\
3 & 1000 & $0.569 \pm 0.011$ \\
4 & 2000 & $1.325 \pm 0.033$ \\
5 & 4000 & $2.570 \pm 0.065$ \\
6 & 8000 & $5.061 \pm 0.034$ \\
\hline
\end{tabular}

${ }^{*}$ Standard deviation.

TABLE 2: Blank responses and the peak areas at LLOQ.

\begin{tabular}{lcc}
\hline Serial number & $\begin{array}{c}\text { Blank response } \\
(\mathrm{mAU} \cdot \mathrm{sec})\end{array}$ & $\begin{array}{c}\text { Peak areas at } \\
\text { LLOQ }(\mathrm{mAU} \cdot \mathrm{sec})\end{array}$ \\
\hline 1 & 3.46 & 38.32 \\
2 & 6.64 & 38.67 \\
3 & 3.47 & 38.02 \\
4 & 3.62 & 37.97 \\
5 & 3.86 & $38 / 16$ \\
6 & 3.63 & 38.95 \\
\hline
\end{tabular}

\section{Results and Discussion}

Chromatographic conditions were selected after several trials on different columns using mobile phases comprised of methanol and acetate buffer at varying $\mathrm{pH}$ and in different proportions. The Shodex C-18-4E column $(250 \times 4.6 \mathrm{~mm}$, $5 \mu \mathrm{m})$ and mobile phase of methanol : acetate buffer $\mathrm{pH} 4$, $20 \mathrm{mM}(90: 10 \mathrm{v} / \mathrm{v})$, gave adequate resolution and satisfactory peak shapes for febuxostat and internal standard. The detection wavelength of $315 \mathrm{~nm}$ was chosen for maximum sensitivity.

When liquid-liquid extraction was performed using different immiscible solvents like diethyl ether, ethyl acetate, and dichloromethane, it was found that both the drug and internal standard were appreciably extracted with diethyl ether. The extraction recovery for febuxostat was $72-75 \%$, while that of diclofenac was 73-78\%.

During calibration experiments it was revealed that the standard deviation of area ratio of CC standards increased with concentration indicating a need for weighted linear regression. The area ratios from calibration experiments are depicted in Table 1.

The use of the unweighted regression calibration model with linear regression equation $Y=0.000633129 X+0.01185$ resulted in heteroscedasticity and a large total \%RE. When weighting factor of $1 / x$ was used, the variances of area ratios of CC standards were homogenized over the calibration range with a decrease in the $\% \mathrm{RE}$. Thus, weighted linear regression with a weighting factor of $1 / X$ was selected as a calibration model which resulted in the equation $Y=0.0006 X+0.0198$. During the validation studies it was found that the peak area for the LLOQ samples was more than five times the blank responses obtained using six different plasma sources, as can be seen in Table 2 . This proved that the method was selective at the LLOQ of $250 \mathrm{ng} / \mathrm{mL}$. The representative chromatogram

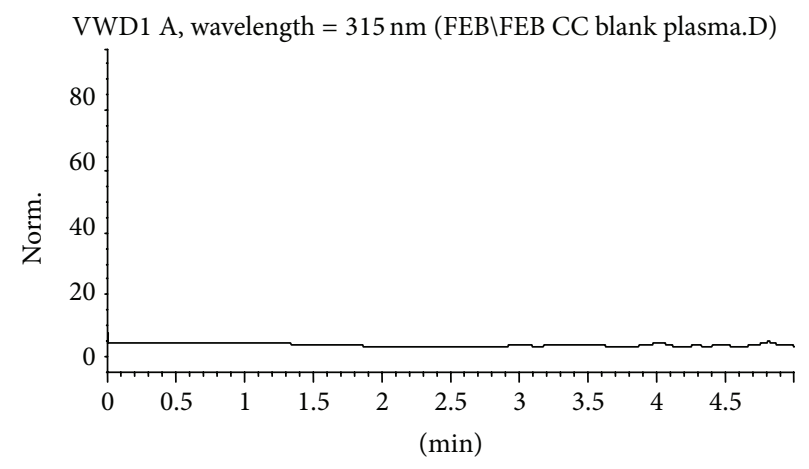

FIGURE 2: Representative chromatogram of blank plasma extract showing a lack of significant interference at the retention times of febuxostat and the internal standard, diclofenac.

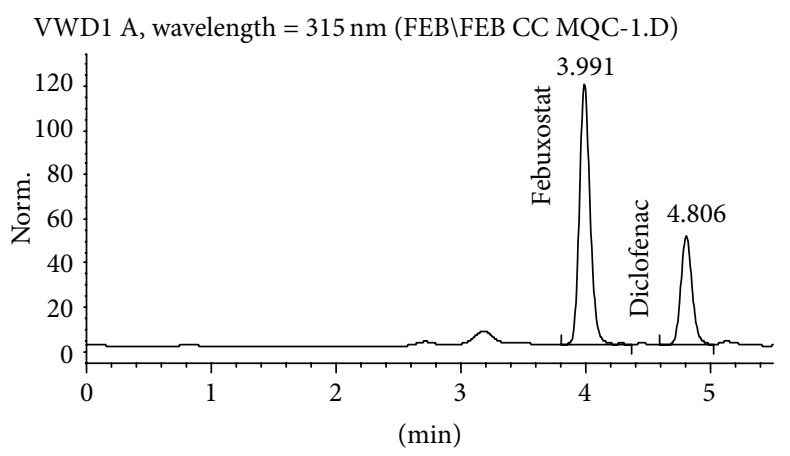

FIGURE 3: Representative chromatogram of MQC sample of febuxostat showing febuxostat $(\mathrm{RT}=3.991 \mathrm{~min})$ and internal standard, diclofenac $(\mathrm{RT}=4.806 \mathrm{~min})$.

of blank plasma shows no interference at the retention times of febuxostat and diclofenac (Figure 2).

The representative chromatogram of a MQC sample of febuxostat (Figure 3) shows both the drug and an internal standard extracted from plasma. The evaluation of accuracy and precision showed that the intraday \%RE was between $+15 \%$ and $-15 \%$, while the $\%$ RSD was less than $15 \%$. The USFDA Guidance requires that the \%RE be between $+15 \%$ and $-15 \%$, while the $\%$ RSD should be less than $15 \%$. The results of assay precision and accuracy as well as extraction recovery for febuxostat at LQC, MQC, and HQC and for internal standard are represented in Table 3.

From the stability studies, it can be concluded, that for each stability study, \% nominal concentration was between 85 and 115 and \%RSD was less than 15, as shown in Table 4, which falls within the acceptable limits. This indicates that the deviation of results from nominal concentration may be attributed to the variability of the assay and imply that the drug had remained stable after stability cycles.

\section{Conclusion}

In this report a rapid, simple, sensitive, and accurate HPLCUV method was described for the determination of febuxostat in spiked human plasma using liquid-liquid extraction. 
TABLE 3: Results of assessment of accuracy, precision, and \%recovery of febuxostat.

\begin{tabular}{lcccccccc}
\hline Level & $\begin{array}{c}\text { Concentration } \\
\text { added }(\mathrm{ng} / \mathrm{mL})\end{array}$ & $\begin{array}{c}\text { Mean } \\
\text { concentration } \\
\text { found }(\mathrm{ng} / \mathrm{mL})\end{array}$ & $\mathrm{RE}^{* 1}, \%$ & $\mathrm{RSD}^{* 2}, \%$ & $\begin{array}{c}\text { Intraday }(n=5) \\
\text { Mean } \\
\text { foncentration }\end{array}$ & $\begin{array}{c}\text { RE, } \% \\
\text { found } / \mathrm{mL})\end{array}$ & $\begin{array}{c}\text { RSD, \% } \\
(n=5)\end{array}$ \\
\hline LQC & 500 & 502.41 & 0.48 & 3.17 & 509.46 & 1.88 & 3.49 & 74.34 \\
MQC & 2000 & 2070.65 & 0.82 & 3.49 & 1902.32 & -4.88 & 3.34 & 72.13 \\
HQC & 7500 & 7640.86 & 1.88 & 4.98 & 7752.68 & 3.37 & 3.17 & 73.98 \\
IS & - & - & - & - & - & - & - & 76.13 \\
\hline$* 1$
\end{tabular}

${ }^{* 1}$ Relative error; ${ }^{* 2}$ relative standard deviation.

TABLE 4: Results of stability studies for febuxostat $(n=5)$.

\begin{tabular}{lccccc}
\hline QC level & \multicolumn{2}{c}{ Stability at room temperature } & \multicolumn{2}{c}{ Stability at $-20^{\circ} \mathrm{C}$} & \multicolumn{2}{c}{ Freeze thaw stability } \\
& \%nominal & \%RSD & \%nominal & \%RSD & \%nominal \\
\hline LQC & 105.53 & 6.9 & 91.43 & 8.7 & 86.21 \\
HQC & 97.36 & 8.1 & 102.89 & 11.1 & 8.8 \\
\hline
\end{tabular}

The method described does not require expensive chemicals and solvents and does not involve complex instrumentation or complicated sample preparation.

The developed method performs well with selectivity, precision, accuracy, stability, and linearity for the concentration range 250 to $8000 \mathrm{ng}$ of febuxostat. The proposed method can be used for routine bioanalysis of febuxostat from plasma to support bioavailability bioequivalence studies.

\section{Conflict of Interests}

The authors declare that there is no conflict of interests regarding the publication of this paper.

\section{Acknowledgments}

The authors would like to acknowledge Jaipur National University and RGS College of Pharmacy for the opportunity to work on this project.

\section{References}

[1] G. Evans, A Handbook of Bioanalysis and Drug Metabolism, edited by G. Evans, CRC Press, Boca Raton, Fla, USA, 2004.

[2] A. R. Buick, M. V. Doig, S. C. Jeal, G. S. Land, and R. D. McDowall, "Method validation in the bioanalytical laboratory," Journal of Pharmaceutical and Biomedical Analysis, vol. 8, pp. 629-637, 1990.

[3] L. R. Snyder, J. J. Kirkland, and J. L. Glajch, Practical HPLC Method Development, John Wiley and Sons, New York, NY, USA, 2nd edition, 1997.

[4] B. G. Smith, A Handbook of Bioanalysis and Drug Metabolism, CRC Press, Boca Raton, Fla, USA, 2004.

[5] S. G. Schulman and S. H. Curry, "Analysis of biologic fluids," in Encyclopedia of Pharmaceutical Technology, J. Swarbrick and J. C. Boylan, Eds., vol. 1, pp. 217-231, Marcel Dekker, New York, NY, USA, 1988.
[6] M. D. Mayer, R. Khosravan, L. Vernillet, J.-T. Wu, N. JosephRidge, and D. J. Mulford, "Pharmacokinetics and pharmacodynamics of febuxostat, a new non-purine selective inhibitor of xanthine oxidase in subjects with renal impairment," American Journal of Therapeutics, vol. 12, no. 1, pp. 22-34, 2005.

[7] V. R. R. Vaka, J. K. Inamadugu, N. R. Pilli, M. Ramesh, and H. R. Katreddi, "A sensitive LC-MS/MS method for the quantification of febuxostat in human plasma and its pharmacokinetic application," Biomedical Chromatography, vol. 27, no. 11, pp. 1406-1412, 2013.

[8] O. Lukram, S. Parmar, and A. Hande, "Determination of febuxostat in human plasma using ultra-performance liquid chromatography tandem mass spectrometry," Drug Testing and Analysis, vol. 5, no. 6, pp. 492-499, 2013.

[9] H. Wang, P. Deng, X. Chen, L. Guo, and D. Zhong, "Development and validation of a liquid chromatography-tandem mass spectrometry method for the determination of febuxostat in human plasma," Biomedical Chromatography, vol. 27, no. 1, pp. 34-38, 2013.

[10] T. Zhang, Y. Sun, P. Zhang, J. Gao, S. Wang, and Z. He, "Ultraperformance liquid chromatography-tandem mass spectrometry method for the determination of febuxostat in dog plasma and its application to a pharmacokinetic study," Biomedical Chromatography, vol. 27, no. 2, pp. 137-141, 2013.

[11] X. Ding, Q. Zhang, Z. Wang, and G. Lin, "Development and validation of liquid chromatography-mass spectrometry method for determination of febuxostat in rat plasma and its application," Latin American Journal of Pharmacy, vol. 31, no. 2, pp. 321-325, 2012.

[12] B. A. Grabowski, R. Khosravan, L. Vernillet, and D. J. Mulford, "Metabolism and excretion of [14C] febuxostat, a novel nonpurine selective inhibitor of xanthine oxidase, in healthy male subjects," Journal of Clinical Pharmacology, vol. 51, no. 2, pp. 189-201, 2011.

[13] R. Khosravan, B. Grabowski, J.-T. Wu, N. Joseph-Ridge, and L. Vernillet, "Effect of food or antacid on pharmacokinetics and pharmacodynamics of febuxostat in healthy subjects," British Journal of Clinical Pharmacology, vol. 65, no. 3, pp. 355-363, 2008.

[14] R. Khosravan, M. J. Kukulka, J.-T. Wu, N. Joseph-Ridge, and L. Vernillet, "The effect of age and gender on pharmacokinetics, 
pharmacodynamics, and safety of febuxostat, a novel nonpurine selective inhibitor of xanthine oxidase," The Journal of Clinical Pharmacology, vol. 48, no. 9, pp. 1014-1024, 2008.

[15] R. Khosravan, B. A. Grabowski, M. D. Mayer, J.-T. Wu, N. Joseph-Ridge, and L. Vernillet, "The effect of mild and moderate hepatic impairment on pharmacokinetics, pharmacodynamics, and safety of febuxostat, a novel nonpurine selective inhibitor of xanthine oxidase," Journal of Clinical Pharmacology, vol. 46, no. 1, pp. 88-102, 2006.

[16] U. S. Department of Health and Human Services, Food, and Drug Administration, Guidance for Industry, Bioanalytical Method Validation, U. S. Department of Health and Human Services, FDA, 2001. 

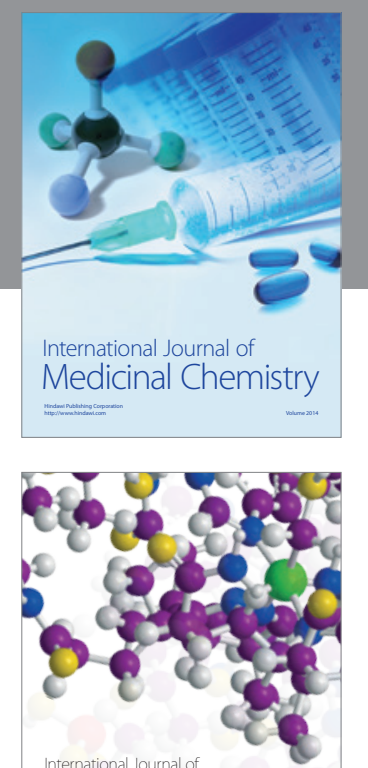

\section{Carbohydrate} Chemistry

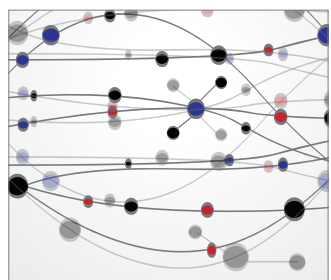

The Scientific World Journal
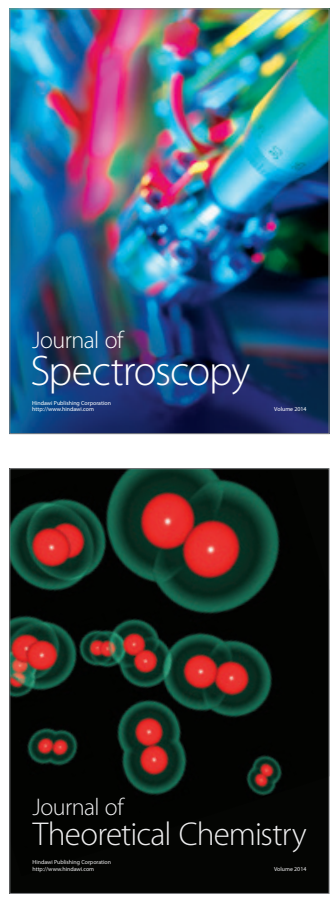
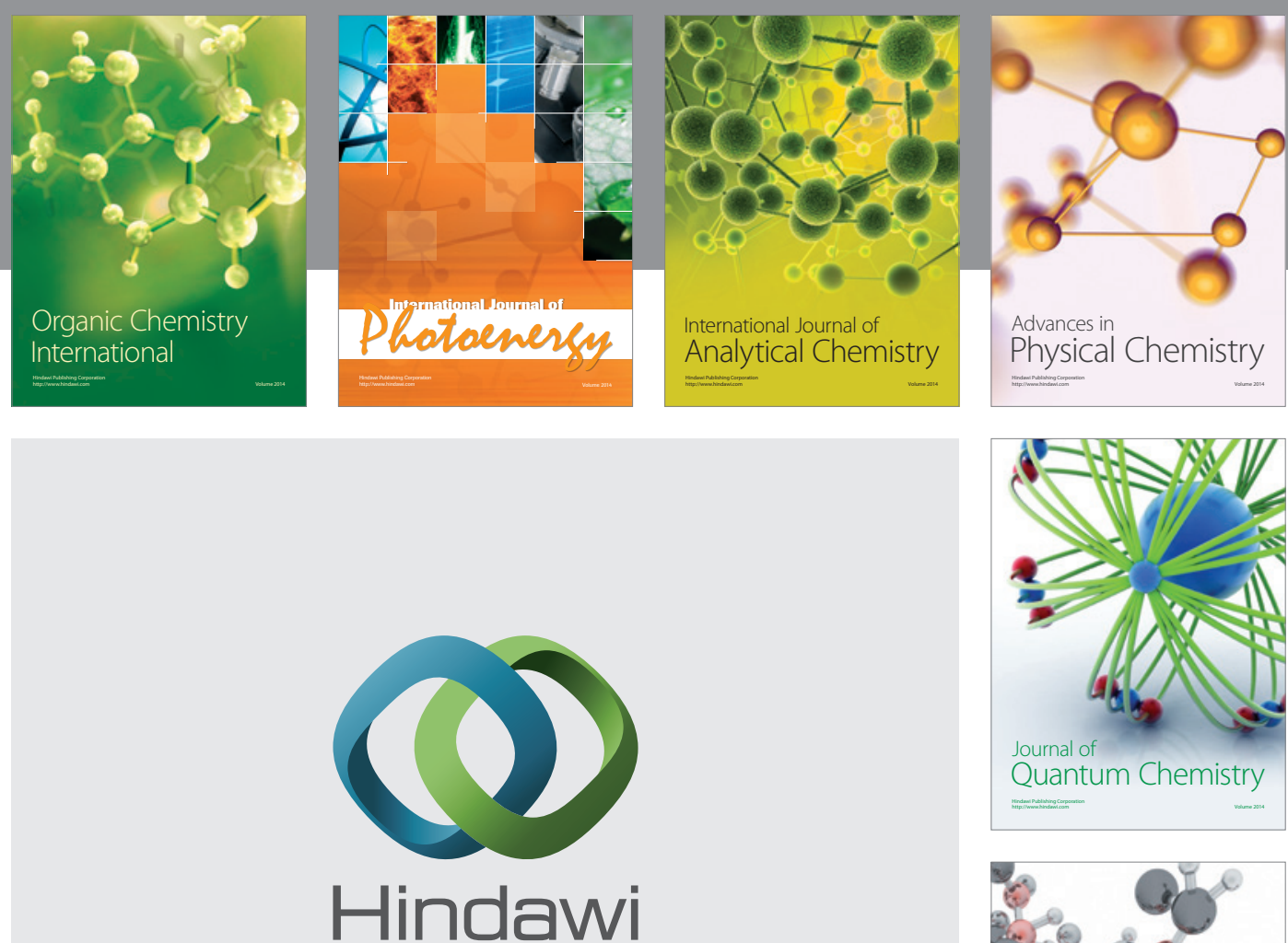

Submit your manuscripts at

http://www.hindawi.com

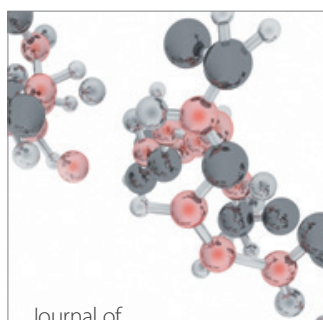

Analytical Methods

in Chemistry

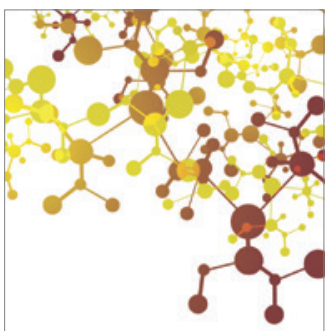

Journal of

Applied Chemistry

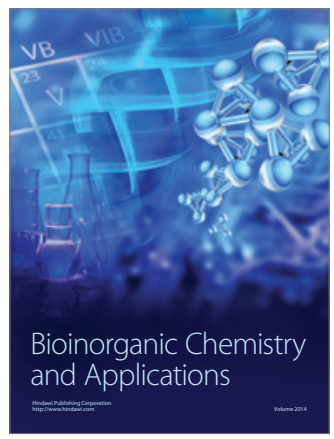

Inorganic Chemistry
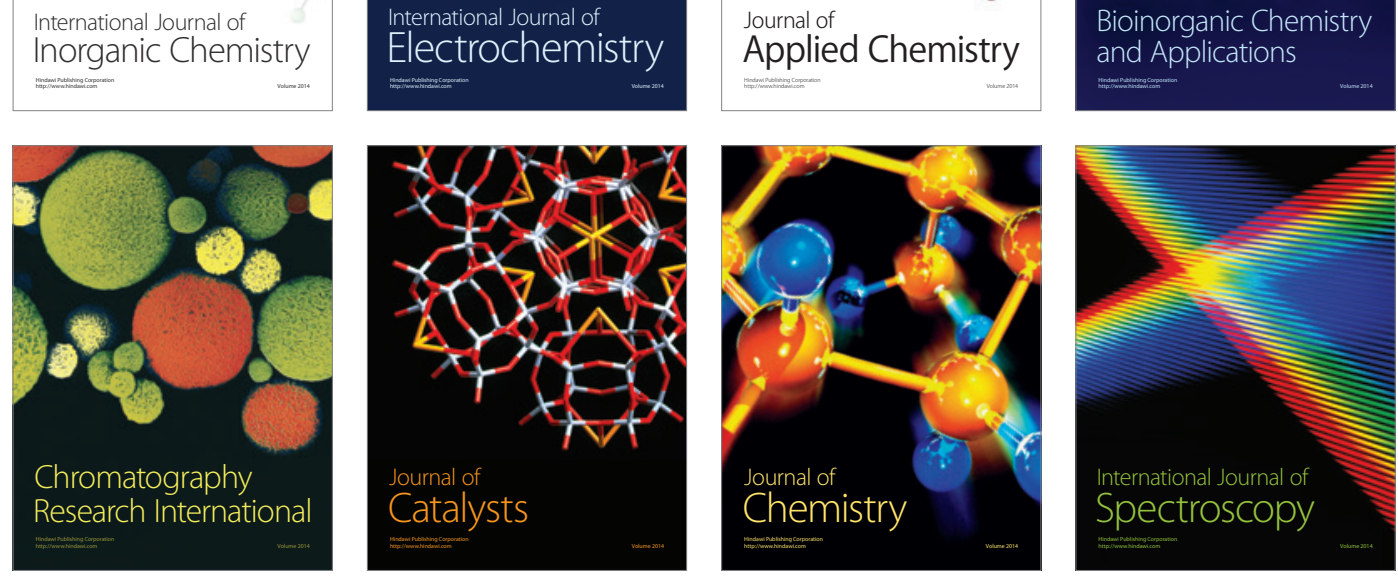